\title{
Demographic Characteristics of Participants in Trials Essential to US Food and Drug Administration Vaccine Approvals, 2010-2020
}

J Gen Intern Med 37(3):700-2

DOI: $10.1007 / \mathrm{s} 11606-021-06670-3$

(C) Society of General Internal Medicine 2021

\section{BACKGROUND AND OBJECTIVE}

Vaccines are a cornerstone of the strategy to address the COVID-19 pandemic. Given disparities in morbidity and mortality from COVID-19 among US populations, calls have been made to ensure representation of those most affected by the disease in trials of new vaccines. Prior research has shown that older adult, Black, and Hispanic participants have historically been underrepresented in clinical trials, including pivotal trials for new drug and device approvals. ${ }^{1,2}$ However, no comparable evaluation of representation in vaccine approvals has been done. This study examines the inclusion of age, sex, racial, and ethnic subgroups and participants with comorbidities in trials essential to new vaccine approvals in the USA.

\section{METHODS}

We identified all novel vaccine products licensed by the US Food and Drug Administration (FDA) between January 2010 and June 2020 for diseases endemic to the USA. ${ }^{3}$ We identified all trials identified as essential to FDA approval of those products in FDA clinical reviews, including efficacy, safety, and lot-to-lot consistency trials. ${ }^{4}$ Using data in clinical reviews, or if not available, in corresponding registration and results reported on ClinicalTrials.gov or publications, we identified the inclusion and exclusion criteria for each trial, then determined the number of participants in each trial and characterized their age, sex, race, and ethnicity. We aggregated trial participants by vaccine approval and, for those trials with subgroup data available, determined the proportions of participants in age, sex, race, and ethnicity subgroups supporting each approval. Participants in pre-2016 trials described as being of Hispanic race were designated as unknown race and Hispanic ethnicity, to allow comparison with trials following more recent guidance on reporting, which specifies Hispanic as an ethnic category. We then characterized the demographic composition of participants, presented in relation to

Received November 3, 2020

Accepted February 14, 2021

Published online March 3, 2021 demographic characteristics of the US population. ${ }^{5}$ Analyses were conducted using R version 3.5.1 (R Foundation for Statistical Computing).

\section{FINDINGS}

From 2010 through 2020, the FDA approved 17 vaccines for diseases endemic to the USA, supported by a total of 40 trials considered essential to approval. Each vaccine was supported by a median of 3 (IQR, 2-4) essential trials with 5241 total participants (IQR, 4281-10423). While no trials used inclusion or exclusion criteria based on sex, race, or ethnicity, age was a common exclusion criteria, with $58.6 \%$ of trials excluding adults 65 or older (95\% CI, 39.6-77.7\%), as were conditions such as pregnancy or lactation $(92.9 \%, 95 \%$ CI, $82.7-$ $100 \%$ ) and comorbidities such as cardiovascular, renal, or hepatic disease (Table 1).

Distributions of participants' age were reported for 32 (80.0\%) trials. Overall, $24.7 \%$ (95\% CI, $0-50.1 \%$ ) of participants were children and $8.5 \%$ (95\% CI, 0-20.7\%) were adults aged 65 years or older, the latter suggesting underrepresentation when compared to the general US population (Table 2). All trials reported participants' sex; $44.8 \%$ (95\% CI, 37.8$51.8 \%$ ) of participants were male, $55.2 \%$ (95\% CI, $48.2-$

Table 1 Exclusion Criteria in Trials Considered Essential to US Food and Drug Administration Approval of New Vaccines, 20102020

\begin{tabular}{ll}
\hline \hline & $\begin{array}{l}\text { Trials excluding, \% (95\% } \\
\text { CI) }\end{array}$ \\
\hline Age-based exclusions $^{*}$ & \\
Pediatric $(<18$ years) & $37.8(21.4-54.2)$ \\
Older Adult ( $\geq 65$ years) $^{\dagger}$ & $58.6(39.6-77.7)$ \\
Pregnancy or lactation-based exclu- & $92.9(82.7-100)$ \\
sions & \\
Comorbidity-based exclusions & \\
Immunodeficiency & $90.0(80.3-99.7)$ \\
HIV infection & $37.5(21.8-53.2)$ \\
Current/past alcohol or drug abuse & $22.5(9.0-36.0)$ \\
Autoimmune conditions & $30.0(15.2-44.8)$ \\
Cardiovascular disease & $20.0(7.0-33.0)$ \\
Renal dysfunction & $17.5(5.2-29.8)$ \\
Hepatic dysfunction & $7.5(0-16.0)$ \\
\hline
\end{tabular}

*Among trials for vaccines expected to include pediatric participants (e.g., excluding vaccines for shingles)

†Among trials for vaccines expected to include older adult participants (i.e., excluding childhood vaccines) 
Table 2 Characteristics of Participants in Aggregated Trials Considered Essential to US Food and Drug Administration Approval of New Vaccines, 2010-2020

\begin{tabular}{|c|c|c|c|}
\hline & \multicolumn{2}{|c|}{$\begin{array}{l}\text { Aggregated trial participants, \% } \\
(95 \% \text { CI) }\end{array}$} & \multirow[b]{2}{*}{$\begin{array}{l}\text { US population } \\
\text { (\%, 2019 US } \\
\text { Census } \\
\text { Estimate) }\end{array}$} \\
\hline & $\begin{array}{l}\text { All vaccine } \\
\text { trials } \\
\text { essential to } \\
\text { approval }\end{array}$ & $\begin{array}{l}\text { Including only } \\
\text { essential trials } \\
\text { intended for use } \\
\text { among } \\
\text { population } \\
\text { subgroups }\end{array}$ & \\
\hline \multicolumn{4}{|c|}{ Age subgroups ${ }^{\dagger}$} \\
\hline $\begin{array}{l}\text { Pediatric } \\
(<18 \text { years })\end{array}$ & $\begin{array}{l}40.5(16.1- \\
64.8)\end{array}$ & $24.7(0-50.1)$ & 22.3 \\
\hline $\begin{array}{l}\text { Adult }(18- \\
64 \text { years })\end{array}$ & $\begin{array}{l}41.7(19.0- \\
64.4)\end{array}$ & $66.7(42.3-91.2)$ & 61.2 \\
\hline $\begin{array}{l}\text { Older } \\
\text { Adult }(\geq 65 \\
\text { years) }\end{array}$ & $\begin{array}{l}17.8(0- \\
36.4)\end{array}$ & $8.5(0-20.7)$ & 16.5 \\
\hline \multicolumn{4}{|l|}{ Sex subgroups } \\
\hline Male & $\begin{array}{l}45.2(39.0- \\
51.4)\end{array}$ & $44.8(37.8-51.8)$ & 49.2 \\
\hline Female & $\begin{array}{l}54.8(48.5- \\
61.0)\end{array}$ & $55.2(48.2-62.2)$ & 50.8 \\
\hline \multicolumn{4}{|c|}{ Race subgroups } \\
\hline White & $\begin{array}{l}70.5(61.4- \\
79.7)\end{array}$ & - & 76.3 \\
\hline Black & $\begin{array}{l}9.2(6.1- \\
12.4)\end{array}$ & - & 13.4 \\
\hline Asian & $6.6(0-13.3)$ & - & 5.9 \\
\hline Other & $5.2(2.0-8.3)$ & - & 4.3 \\
\hline \multicolumn{4}{|c|}{ Ethnicity subgroups ${ }^{\S}$} \\
\hline Hispanic & $\begin{array}{l}19.2(11.7- \\
26.8)\end{array}$ & - & 18.5 \\
\hline $\begin{array}{l}\text { Non- } \\
\text { Hispanic }\end{array}$ & $\begin{array}{l}80.7(73.2- \\
88.3)\end{array}$ & - & 81.5 \\
\hline
\end{tabular}

*For age, this excludes trials supporting 5 childhood vaccine approvals and 1 shingles vaccine approval, leaving 21 essential trials supporting 11 vaccine approvals for analysis. For sex, this excludes 1 essential trial examining only the cervical cancer endpoint for Gardasil 9 approval, leaving 39 essential trials supporting 17 vaccine approvals for analysis †Age subgroup data was available for 32 essential trials supporting 16 of 17 vaccine approvals

$\ddagger$ Race subgroup data was available for 39 essential trials supporting 17 vaccine approvals. Percentages may not sum to $100 \%$, as data for participants with unknown race are not included in the table

SIncluding participants whose race was not explicitly defined, such as those participants in pre-2016 identifying as Hispanic in trials designating Hispanic as a racial category

"Ethnicity subgroup data was available for 33 essential trials supporting 15 vaccine approvals.

$62.2 \%)$ female. Information about participants' race and ethnicity was reported for $39(97.5 \%)$ and $33(82.5 \%)$ trials, respectively. Among these, $70.5 \%$ of participants identified as White (95\% CI, 61.4-79.7\%), 9.2\% as Black (95\% CI, 6.1$12.4 \%$ ), and $6.6 \%$ as Asian (95\% CI, $0-13.3 \%$ ), suggesting underrepresentation among Black participants (Table 2); 19.2\% identified as Hispanic (95\% CI, 11.7-26.8\%).

\section{DISCUSSION}

Among trials considered essential to FDA approval of 17 vaccines for diseases endemic to the USA from 2010 through 2020 , we found that exclusion criteria based on older age and prevalent comorbidities were commonly used, and there was underrepresentation of Black and older adult participants, but not female or Hispanic participants. Our finding of disparities in participation and gaps in reporting in vaccine trials are consistent with those seen among recent FDA approvals of drugs and medical devices. ${ }^{1,2}$

This study examined only demographic composition of vaccine trials essential to FDA approval and does not account for enrollment in other supportive pre-market trials that were ongoing or completed at the time of approval. While we reviewed all vaccine approvals over the past 10 years, there were a limited number of vaccines endemic to the USA on which to base our study. Nonetheless, as COVID-19 vaccine testing and evaluation proceeds, our study reinforces recent FDA guidance to include in COVID-19 vaccine trials diverse populations of participants from communities most affected by the disease - particularly racial and ethnic minorities, older adults, and individuals with comorbidities. ${ }^{6}$

Acknowledgements: Dr. Zhang had full access to all the data in the study and takes responsibility for the integrity of the data and the accuracy of the data analysis.

Audrey D. Zhang, $M D^{1}$

Jeremy Puthumana, $M D^{2}$

Alexander C. Egilman, $B A^{3}$

Jason L. Schwartz, PhD ${ }^{4}$

Joseph S. Ross, MD, MHS ${ }^{2,3,4}$

${ }^{1}$ Department of Medicine, Duke University School of Medicine,

Durham, NC, USA

${ }^{2}$ Department of Internal Medicine, Yale University School of Medicine,

New Haven, CT, USA

${ }^{3}$ Center for Outcomes Research and Evaluation, YaleNew Haven Health System,

New Haven, CT, USA

${ }^{4}$ Department of Health Policy and Management, Yale School of Public Health,

New Haven, CT, USA

Corresponding Author: Joseph S. Ross, MD, MHS; Department of Internal Medicine, Yale University School of Medicine, New Haven, CT, USA (e-mail: joseph.ross@yale.edu).

Author's contributions Drs. Zhang, Schwartz, and Ross were responsible for the conception and design of this work. Dr. Zhang drafted the manuscript and performed the statistical analysis. Drs. Zhang and Puthumana and Mr. Egilman were responsible for the acquisition of data. All authors participated in the analysis and interpretation of the data and critically revised the manuscript for important intellectual content. Dr. Zhang is the guarantor.

\section{Declarations:}

Conflict of Interest: In the past 36 months, Dr. Zhang, Mr. Egilman, and Dr. Ross received research support through Yale University from the Laura and John Arnold Foundation for the Collaboration for Research Integrity and Transparency (CRIT) at Yale and currently receive support from the Food and Drug Administration for the Yale-Mayo Clinic Center for Excellence in Regulatory Science and Innovation (CERSI) program (UO1FD005938); Dr. Ross received research support through Yale University from Medtronic, Inc. and the Food and Drug 
Administration (FDA) to develop methods for postmarket surveillance of medical devices (UO1FD004585) and from the Centers of Medicare and Medicaid Services (CMS) to develop and maintain performance measures that are used for public reporting (HHSM-500-2013-13018I); Dr. Ross currently receives research support through Yale University from Johnson and Johnson to develop methods of clinical trial data sharing, from the Medical Device Innovation Consortium as part of the National Evaluation System for Health Technology (NEST), from the Agency for Healthcare Research and Quality (RO1HSO22882), from the National Heart, Lung and Blood Institute of the National Institutes of Health (NIH) (RO1HSO25164, RO1HL144644), and from the Laura and John Arnold Foundation to establish the Good Pharma Scorecard at Bioethics International. Drs. Puthumana and Schwartz have no competing interests to disclose.

\section{REFERENCES}

1. Downing NS, Shah ND, Neiman JH, Aminawung JA, Krumholz HM, Ross JS. Participation of the Elderly, Women, and Minorities in Pivotal Trials Supporting 2011-2013 U.S. Food and Drug Administration Approvals. Trials. 2016;17:199-210.
2. Dhruva SS, Mazure CM, Ross JS, Redberg RF. Inclusion of DemographicSpecific Information in Studies Supporting US Food \& Drug Administration Approval of High-Risk Medical Devices. JAMA Intern Med. 2017 Sep $1 ; 177(9): 1390-1$.

3. Center for Biologics Evaluation and Research. Vaccines Licensed for Use in the United States. FDA [Internet]. 2020 Apr 24 [cited 2020 Oct 7]; Available from: https://www.fda.gov/vaccines-blood-biologics/vaccines/vaccines-licensed-use-united-states

4. Puthumana J, Egilman AC, Zhang AD, Schwartz JL, Ross JS. Speed, Evidence, and Safety of Vaccines Approved by the US Food and Drug Administration. JAMA Intern Med. 2020 Nov 10;e207472. https://doi. org/10.1001/jamainternmed.2020.7472

5. U.S. Census Bureau Quick Facts: United States [Internet]. United States Census Bureau. 2020. Available from: https://www.census.gov/ quickfacts/fact/table/US/PST045219

6. US FDA. Development and Licensure of Vaccines to Prevent COVID-19: Guidance for Industry. 2020 p. 24.

Publisher's Note: Springer Nature remains neutral with regard to jurisdictional claims in published maps and institutional affiliations. 